\title{
Patients with incidental findings on MPS CTAC
}

We were enthused in our reading of the work of Zadro et al. ${ }^{1}$ We have investigated this topic ourselves and recently published a case series of lung cancers discovered in this fashion ${ }^{2}$-on the low-dose computed tomography scan for attenuation correction (CTAC) as a component of myocardial perfusion scintigraphy (MPS). Our study population was different (being Australian) but the conclusion derived was the same-that MPS CTAC images should certainly be reviewed and incidental findings further investigated and/or followed up as clinically appropriate-whether this be by the cardiac or family physicians initiating the MPS or the respirologists to whom they refer subsequently.

On our reading, we had some further enquiries-to further check if a similar experience to our own was noted.

(1) Was there a similar incidence of extracardiac findings-especially malignancies-compared to the rest of the population?

(2) Do patients with malignancies, for example, lung cancer, detected on MPS have a similar risk factor and demographic profile to those discovered by other means (whether it is clinically or on other imaging)?

(3) Were the patients with significant extracardiac findings more (or less) likely to have significant concurrent ischaemic heart disease?

Joseph C. Lee, MBBS, FRACP, FAANMS, ${ }^{a, b}$

Francis T. Delaney, MBBS

${ }^{a}$ Department of Medical Imaging, The Prince Charles Hospital, Chermside, QLD 4032, Australia; joseph.lee@health.qld.gov.au

${ }^{b}$ Faculty of Medicine, University of Queensland, St Lucia, QLD 4072,

Australia

${ }^{c}$ Department of Radiology, Mater Misericordiae University Hospital, Eccles St, Dublin D07 R2WY, Ireland

\section{Author Contribution}

Conception or design of the work, or the acquisition, analysis, or interpretation of data for the work: JCL $60 \%$ and FTD $40 \%$. Drafting the work or revising it critically for important intellectual content: JCL 60\% and FTD 40\%

\section{Disclosure}

Joseph Lee and Francis Delaney have indicated that they have no financial conflict of interest.

\section{References}

1. Zadro C, Roussel N, Cassol E, Pascal P, Petermann A, Meyrignac $\mathrm{O}$, et al. Prognostic impact of myocardial perfusion single photon emission computed tomography in patients with major extracardiac findings by computed tomography for attenuation correction. J Nucl Cardiol 2018;25:1574-83.

2. Delaney FT, Fong KM, Lee JC. Primary thoracic cancers incidentally detected on CT attenuation correction images during myocardial perfusion scintigraphy. Clin Lung Cancer 2018;19:e575-9.

doi:10.1007/s12350-018-01500-2

J Nucl Cardiol 2019;26:1015.

$1071-3581 / \$ 34.00$

Copyright (C) 2018 American Society of Nuclear Cardiology. 